\title{
Development and knowledge for assessing the stability of rock masses and rock slopes in Bulgaria
}

\author{
Radoslav Varbanov ${ }^{1}$, Alexander Hristov ${ }^{2}$
}

${ }^{1}$ University of Architecture, Civil Engineering and Geodesy (UACEG); e-mail: r_varbanov@mail.bg ${ }^{2}$ University of Mining and Geology ,St. Ivan Rilski“, Sofia, Bulgaria

\section{Развитие и познания за оценка на} устойчивостта на скални масиви и скални откоси в България

\author{
Радослав Върбанов, Александър Христов
}

Varbanov, R., A. Hristov. 2020. Development and knowledge for assessing the stability of rock masses and rock slopes in Bulgaria. Engineering Geology and Hydrogeology, 34, 67-76.

\begin{abstract}
This article examines the stages of construction of infrastructure in Bulgaria. Much of the existing railway infrastructure was built in the late 19th and early 20th centuries, when in practice there were no formulated requirements for assessing the stability of rocky slopes and workings carried out in rocky terrains. For this reason, the development of different methods for assessing the construction qualities of rock massifs is being considered. It is stated that the first methods for estimating the rock massifs are based only on the engineering-geological properties of the rocks, but not on their geostructural features. The development of methods for assessing the stability of tunnels and rock excavations, as well as the entry into them of necessary data from studies on the geostructural properties of rock massifs, are considered. Examples are given of the use of different methods in the assessment of the stability of rock slopes and tunnels in Bulgaria. It is emphasized that in the latest publications, the properties of the rock masses and their stability are described on the basis of the latest knowledge in the field of geostructural geology, geotechnics and normative documents.
\end{abstract}

Keywords: rock slopes, tunnels, slope stability, geostructural analysis.

Резюме. Настоящата статия разглежда етапи от строителството на инфраструктурни обекти в България. Голяма част от съществуващата железопътна инфраструктура е изградена в края на $19^{\text {ти }}$ и началото на $20^{\text {ти }}$ век, когато на практика не е имало формулирани изисквания за оценка на устойчивостта на скални откоси и изработки, прокарани в скални терени. Поради тази причина се разглежда развитието на различните методи за оценка на строителни качества на скалните масиви. Посочено е, че първите методи за оценка на скалните масиви се базират само на инженерногеоложките свойства на скалите, но не и на техните геоструктурни особености. Разгледано е развитието на методите за оценка на устойчивостта на тунелни изработки и скални изкопи, както и навлизането в тях на необходими данни от проучвания за геоструктурните свойства на скалните масиви. Посочени са примери за използването на различни методи при оценката на устойчивостта на скални откоси и тунели в България. Подчертано е, че в най-новите публикации, се описват свойства на скалните масиви и тяхната 
устойчивост на базата на най-новите познания в областта на геоструктурната геология, геотехника и нормативи документи.

Ключови думи: скални откоси, тунели, склонова устойчивост, геоструктурен анализ.

\section{Въведение}

Оценката на устойчивостта на скални масиви и скални откоси, включва в себе си необходимостта от познания в различни области от най-общо казано „Науки за Земята“. При оценката на скални масиви и скални откоси са необходими познания по структурна геология за определяне на прекъснатостите в масива и тяхната пространствена ориентация. Необходими са познания по литология и стратиграфия за описание на скалния масив, по инженерна геология и хидрогеология за определяне инженерногеоложкото и хидрогеоложко състояние на масива, както и на якостните и деформационни свойства на масива, по скална строителна механика за оценка на състоянието и устойчивостта на разглеждания обект.

Предстои изпълнението на значителен по обем проекти, свързани с развитието на пътната и железопьтна инфраструктура. Проектите включват изграждането на значителен брой тунели, свързаните с тях откоси в зоната на порталните изкопи, оформяне на значителни по височина изкопи в различни скални терени, както и тяхното укрепване. Съществени познания в посочените по-горе области се изискват и при проектиране на скалните откоси в редица открити рудници, скални кариери и др.

Всичко това провокира необходимостта от един кратьк преглед на методиката за описание на скалните масиви, методиката за оценка на техните инженерногеоложки и хидрогеоложки качества и методиката за определяне на тяхната устойчивост в бъдещите изкопи и тунели. За съжаление, публикациите в посочените по-горе области, не са много и са твърде едностранно насочени. Тематиката е предимно към разглеждане на един или два проблема от описанието и устойчивостта на скалните масиви и откоси, като в тях липсва част от необходимата информация за оценка на масивите.

Целта на настоящата статия е да се направи преглед на част от публикациите по повдигнатите въпроси и да се посочат най-новите тенденции в развитието на този дял от познанието за скалните масиви.

\section{Преглед на методите за описание и оценка на скални масиви}

С развитието на пътната и железопътна мрежа в България, първите тунели и укрепени скални откоси в България са изградени по ж.п. линия София - Роман. Линията езавършена през 1897 г., като са построени 23 тунела. Следва завършване на ж.п. линия Русе-Подкова, като участъка до Дъбово е предаден през 1913 г. Изградени са общо 17 тунела. В областта на пьтното строителство, през 1883 г. княз Александър I утвърждава „Закон за направата, поправката и поддръжката на окръжните пътища“". По данни на АПИ, пътните тунели в България са 32. Нямаме данни, кои са първите изградени тунели и укрепени скални откоси по пътна мрежа.

В историческите сведения има описание за историята на строежите, но не и описание на методите за оценка на геоложките, инженерногеоложките и хидрогеоложки условия и оценка на скалните масиви. По време на посочените ж.п. строежи, вероятно не е имало указания и правилници за извършване на описаните по-горе оценки.

В настоящата инженерна практика се използват редица класификационни системи за оценка на качеството на скалния масив, които поставят различни акценти върху различните параметри. Препорьчва се при класификацията на 
скалния масив, за всеки обект, да се ползват поне два метода в ранните етапи на проектиране.

Една от първите и най-разпространената класификация на скалите по якост е предложена в началото на XX век. Проф. М. М. Протодяконов през 1926 г. предлага класификация на всички скали по тяхната якост (Protodyakonov, 1931). Класификацията се основава на факта, че устойчивостта на скала́та срещу всякакъв вид разрушения може да бъде изразена с едно конкретно число коефициентът на якост на скала́та $(f)$, който показва колко пъти силата на дадена скала е по-голяма или по-малка от якостта на скала́та, приета като единица. За $f=1$ се приема, че якостта на едноосов натиск на скала́та е $10 \mathrm{MPa}\left(100 \mathrm{~kg} / \mathrm{cm}^{2}\right)$. Тази класификация добива широко приложение при проектирането и строителството на значителен брой хидротехнически съоръжения и тунели.

На базата на многобройни изследвания е определена якостта на едноосен натиск и други инженерногеоложки характеристики на значителен брой скални терени, а при проектирането е извършена и класификация на скалните масиви (Antonov et al., 1955).

През 1946 г. е предложено за класификацията на скалните масиви да се ползват описателни методи на геотехническите характеристики на скалите (Terzaghi, 1946).

Описанията на характеристиките на скалния масив са ясни и кратки. Те дават добър пример за необходимите данни, които следва да се представят във един инженерногеоложки доклад, необходим за проектиране на укрепителни конструкции. Съвсем накратко тези определения описват вида на скалния масив, неговата степен на напуканост и пространственото разположение на пукнатините, както и степента на изветряне на масива.

Класификация на скални масиви за проектиране на облицовката на тунели е предложена през 1958 г. (Lauffer, 1958). Тя е подходяща само за тунелни крепежни облицовки и е залегнала по-късно в „Нов австрийски метод за прокарване на тунели“".

Качествен показател за класифициране на сондажната ядка (RQD) е предложен от Deere през 1964 (Deere et al., 1967). Самият качествен показател RQD се дефинира като съотношение (в проценти) от общата дължина на парчетата от сондажната ядка, които са по-дълги от 0,1 m (4 инча), спрямо дължината на изследвания интервал от сондажа. Освен директният метод за определяне на RQD от сондажната ядка, съществуват и различни индиректни методи за оценка на RQD.

Количествен метод за описание на качеството на скалната маса - Rock Structure Rating (RSR) е предложен през 1972 г. (Wickham et al., 1972). Тази система за класифициране на скалния масив е подходяща за правилния избор на подходящо укрепване на тунели. Класификацията на масива се извършва на базата на три показателя - RSR=A+B+C. Най-общо, RSR система включва: геоложка оценка на масива A - произход на скалите, изграждащи скалния масив, якост на скалите; В - геоложка структура на скалния масив в зависимост от степента му на засегнатост от тектонски процеси, геометрия на пукнатините и тяхната ориентация спрямо тунелната изработка, размери и ориентация на пукнатините и $\mathrm{C}$ - хидрогеоложки условия (наличие на подземни води, очакван воден приток).

Класификация на скалните масиви по геомеханични признаци е публикувана през 1976 г. (Bieniawski, 1973). Известна е като „Геомеханична класификация или система за класификация на скалния масив (RMR). C течение на годините тази система се усъвършенства последователно. Направена е значителна промяна в оценките, присвоени на различни параметри (Bieniawski, 1976; Bieniawski, 1989). Следващите шест параметъра, използвани за класифициране на скални масиви, 
са сьгласно версията от 1989 г. Тези параметри включват както чисто геоложки оценки на масива, така и якостни и деформационни характеристики на скалите, които го изграждат. Това са: якост на едноосен натиск; качество на скалния масив (RQD), разстояние между прекъсванията, състояние на прекъсванията, ориентация на прекъсванията и хидрогеоложки условия.

Въз основа на опита от оценка на голям брой случаи на подземни изкопи от Норвежкия геотехнически институт предлагат индекс за оценка качество на скала́та в тунелните изработки (Q) - (Barton et al., 1974). На практика, класификацията се основава на времето, което е необходимо за да настъпи начало на разрушаване на скалния масив в тунелния изкоп.

$$
Q=\frac{R Q D}{J_{n}} \frac{J_{r}}{J_{a}} \frac{J_{w}}{S R F}
$$

където:

RQD е обозначението за качество на скалния масив;

Jn - оценка за напукаността на масива;

$\mathrm{Jr}$ - оценка за грапавостта на пукнатините (прекъснатостите);

Ja - оценка за степента изменение на стените на прекъснатостите;

Jw - оценка за хидрогеоложките условия в прекъснатостите;

$\mathrm{SRF}$ - редукционен коефициент за напреженията в масива.

Числовата стойност на индекса Q се оценява в логаритмична ска́ла от 0,001 до максимум 1000 (Barton et al., 1980; Barton et al., 1992).

В посочената класификация за първи път е посочена възможността за оценка на скалните масиви, свързана с устойчивостта не само за тунелни изработки, но и на скални изкопи. Свързвайки стойността на индекса Q с изискванията за стабилност и укрепване на подземни изработки, авторите определят допълнителен параметър, който наричат еквивалентно измерение (De) на изкопа (Barton et al., 1974). Този размер зависи от височината и диаметъра или размерите на стена на изкопа.

Досега, двете най-широко използвани класификации на скалните масиви са RMR на Bieniawski $(1976,1989)$ и Q метода (Barton et al.,1974). И двата метода включват геоложки, геометрични и конструктивни/инженерни параметри за постигане на количествена стойност на качеството на скалния масив.

За България, може да се приеме, че първата методика за инженерногеоложки и скално-механични проучвания на скални изкопи е изготвена през 1985 г. от колектив при ВИАС с ръководител проф. Н. Косев. Методиката е изготвена по договор между НИПС при ВИАС (дог. 0-58/82) и ГУП при Министерство на транспорта. Методиката е предназначена за проектантските организации, свързани с проучването и проектирането на съоръжения (тунели, изкопи и др.), преминаващи през различни скални масиви. В методиката е залегнала необходимостта от изясняване на характеристики на скалния масив като произход, класификация на скалите по различни признаци, определяне на геометричните характеристики на прекъснатостите в масива и тяхното състояние, хидрогеоложки условия, якостни и деформационни характеристики на скалите, кинематичната схема на изучавания скален масив и др., като е посочен препоръчителен обем на инженерногеоложките и скално-механични проучвания, както и методика за предварителна оценка на устойчивостта на скални изкопи. В нея е залегнала и оценката на качеството на скала́та RQD. На практика, тази методика има ведомствен характер и не е известна на широк кръг специалисти, имащи проблеми с проучването и оценката на скални масиви и проектиране на укрепителните конструкции. 
Наред със съществуващите класификации на скалните масиви, развитието на строителните и минни дейности налагат необходимостта от нова класификация за много слабите тектонски нарушени скални маси, свързани с основните планински вериги на Алпите, Хималаите и Андите. На практика този проблем е решен с въвеждането на понятието „Индекс на геоложката якост“ GSI (Hoek, Bray, 1981).

Тази класификация отчита само естествените геоложки характеристики на скалния масив. Подробна информация за процедурата за използване на тази класификация може да се намери в публикациите: „The Hoek-Brown failure criterion and GSI", 2018; E.Hoeka and E.T.Brownb, Journal of Rock Mechanics and Geotechnical Engineering, Volume 11, Issue 3, June 2019, Pages 445-463.

Оценката на скалните масиви по GSI е разширена с течение на времето и натрупване на допълнителен опит. Тя е допълнена и разширена, за да отчете геоложките условия за силно нагънати скални масиви, тектонски дислокации и силно натрошени зони ( Hoek et al., 1998; Hoek, Marinos, 2000; Marinos, Hoek, 2000; Marinos, Hoek, 2001; Hoek et al., 2005; Marinos et al., 2005; Marinos, 2017; Marinos, Carter, 2018).

Някои основни понятия за извършване класификацията на скални масиви за различни видове строителство и определяне на тяхната устойчивост са залегнали в изискванията на БДС EN ISO 14689-1 за описание и класификация на скалите.

От посочените методики за оценка на устойчивостта на скални масиви при прокарване на тунелни изработки, скални изкопи и др. се вижда, че с течение на времето предложените методики обхващат все по-широк кръг от необходими познания за първоначално натрупване на данни и последваща оценка на устойчивостта.

Посочените методики могат да се ползват и при решаване на въпроси с устойчивостта на скални изкопи в рудници, кариери, пътни и жп откоси, оценка на устойчивостта на паметници на културата, изградени във и върху опасни скални откоси и др.

\section{Оценки на устойчивостта на естествени и изкуствени скални откоси в България}

Посочените методики могат да се ползват за оценка на състоянието на различни по произход скални откоси в природа, както и такива, оформени при строителни работи и тунелни изработки.

Дълги години въпросите за състоянието на скалните масиви са разглеждани самостоятелно. От една страна, посочените по-горе системи за оценка на качеството на масива са използвани в минното и тунелно строителство, като, поради липса на специализирани инженерногеоложки проучвания и/или липса на необходимите познания, определянето на стойностите на тези показатели се е извършвало в голяма степен експертно от съответните минни или тунелни проектанти без или с ограничената експертиза на инженерите геолози. За тунели, това най-често се е извършвало (и все още се извършва) по най-старата и твърде обща методика на Протодяконов, чиято разширена и допълнена версия, взета от „Руководство по проектированию гидротехнических туннелей“ (1982) е включена в Норми за проектиране на пътни и железопътни тунели от 1988 г. и е все още валидна в частта си за железопътни тунели.

Успоредно с това, проблемите за устойчивостта на скалните откоси в открити рудници са решавани на базата на общи или числени методи (МКЕ), основаващи ce на практически експертно определяне на якостните и деформационни показатели на масива (Koseva et al., 1984).

Основно от 90-те тодини на миналия век, въпросите на устойчивостта 
на скални откоси у нас са разглеждани основно по отношение на пътното и жп стрителство на базата на оценка на структурно контролираната и обща устойчивост на единични или групи от няколко скални блока, чиято устойчивост се определя от съпротивленията на срязване по прекъснатости (пукнатини и др.). Значителен брой изследвания и резултати (вкл. полеви и лабораторни опити, и модели за якост на срязвяне по пукнатина) са извършени от Г. Илов, и др. (Много подробна справка е представена в Илов (Ilov, 2004).

По-късно (след 1990 г.) се провеждат значителни по обем и съдържание инжнерногеоложки проучвания за оценки на устойчивостта на естествени скални откоси, носещи или свързани с опазване на недвижими паметници. Много често, те се намират под въздействието на естествени разрушителни геоложки и антропогенни процеси, които са неблагоприятни за тяхната устойчивост. Поради тези причини, възниква проблемът с тяхното възстановяване и съхраняване за бъдещите поколения. Едни от най-застрашените от разрушаване недвижими паметници на културата са Рилският и Преображенският манастир, Скалният релеф в зоната на „Мадарския конник“, скалната църква „Св. Богородица“ при с. Иваново, Русенско, „Аладжа манастир“ при КК „Златни пясъци, Цьрквата „Св, Четиридесет мъченици“ във Велико Търново, и др. В една или друга степен паметниците са повредени. Поради тези причини, инженерногеоложките условия и геотехнически характеристики на скалните масиви, в които те са изградени, са били обект на изследване от различни колективи.

Един от най-изучаваните паметници на културата е "Мадарския конник" който е част от природно наследство на ЮНЕСКО. Барелефът е изсечен на отвесна скала́ близо до днешното село Мадара в Североизточна България. Склонът е с вертикален наклон и височина около $103 \mathrm{~m}$. Скалният масив е изграден от горнокредни пясъчници, разположени върху мергели със същата възраст. С течение на годините са се образували дълбоки вертикални пукнатини. Успоредно на склона са оформени три скални блока, лежащи върху мергелите, които се определят като полускална основа (Frangov et al., 1992). Публикувани са данни за геоложките и тектонски характеристики на района, състоянието на скалния масив, склоновите процеси и изветрянето на скалния масив, геотехнически характеристики на някои от скалните и полускални седименти. Изяснено е напрегнатото състояние на масива и неговата устойчивост (Angelov et al., 1993). Поради развиващи се деформации на склона във времето (Konstantinov et al., 2003) посочват геотехнически проблеми на недвижимите паметници на културата в България. Състоянието на склона се следи чрез продължителни мониторингови наблюдения (Dobrev et al., 2008).

Друг проблем на паметниците на културата е устойчивостта на редица манастири в България.

Един от манастирите, засегнати от срутищни процеси, е Преображенският манастир край Велико Търново. Той е четвъртият по големина манастир в България. Изграден е в подножието на стръмен планински склон, изграден от варовици, залягащи върху полускална подложка от мергели и пластове от пясъчник. С течение на времето, скалният откос от варовици частично загубва своята устойчивост, при което възникват срутищни процеси, разрушили манастирски сгради (Konstantinov et al., 1996). Изяснена е динамиката на възникване на пукнатинните системи в скалния откос, пространственото разположение на прекъснатостите в масива и неговата устойчивост.

Към скалните манастири се отнася и „Аладжа манастир“. Той е издълбан в скален откос от варовик, разположен в източната периферия на Франгенското плато, близо до град Варна, СЕ България. Тази част от платото е заплашена от различни разрушителни процеси, които заличават бавно и безпощадно 
това значимо историческо място (Dobrev, Frangov, 2000; Frangov, Dobrev, 2000). Изяснени са разпределението, динамиката, механизмът и влиянието на различните геодинамични процеси, засегнали манастира.

Скалната църква „Св. Богородица“ при с. Иваново, Русенско е част от древен религиозен комплекс, оформен във варовикова скала́ на каньон на река Русенски Лом в СЕ България. Църквата е оформена в скала́та около 1320 г. сл. Хр. Тя е един от деветте Български паметника, включени в регистъра на ЮНЕСКО за световно културно наследство. Скалната основа е естествено нарушена и опасна от гледна точка за възникване на съвременни геодинамични процеси. Изяснен е геоструктурният модел на скала́та и възможните взаимодействия между отделните скални блокове. Чрез полеви опити (Lakov, Paskaleva, 2009) е определена якостта на срязване по прекъснатостите в масива. Проведено е и сеизмично микрозониране на обекта (Paskaleva et al., 2009).

Всички скални откоси в разгледаните зони на паметниците на културата са застрашени от възникване на срутищни процеси. Изготвен е и методичен подход за картографирането на скални масиви по податливост към проявата на струтищни процеси (Ivanov et al., 2018).

Може да се приеме, че едни от първите публикации, свързани с използването не геоложки и геоструктурни модели за оценка на устойчивостта на откосите на открити рудници и кариери, са след 2011. По посочената методика са определени устойчивите откоси на кариери и рудници като „Юртдере”, „Елаците“, „Гранитово“ и др. (Jelev et al., 2011; Lakov et al., 2011; Dobrev et al., 2012; Sachkov et al., 2012).

След 2010-2015 г. в България започва да се реализира значително по обем инфраструктурно строителство. Започва строителството на много магистрали и нови, високоскоростни ж.П. линии. Свързаното с това строителство е съпроводено с включване на чуждестранни консултанти, проектанти и строители, като поставя значително по-високи изисквания към проучванията на скалните масиви при изграждане на нови пътни и железопътни тунели. Основен акцент се поставя върху определяне на индекса на геоложката якост (GSI) (Hoek, Bray, 1981), основаващ се изцяло на структурно-геоложки параметри като степен на напуканост на скалния масив и състояние на пукнатините, както и свързаните с него параметри на якостния модел на Hoek и Brown (1980) и методите за оценка на якостно-деформационните условия на нарушената скала.

Проучването на тези съоръжения е извършено в съответствие с изискванията на БДС EN ISO 14689-1 за описание и класификация на скалните маси и използването на получените геоструктурни модели за проектиране на укрепването на съорьженията. Получени са нови данни за геоложкия строеж, геоструктурната обстановка и геотехнически характеристики на скалните масиви в зоната на Кресненското дефиле (Lakov, Stoynev, 2015; Lakov, Stoynev, 2018) и скалния масив южно от Благоевград (Lakov, Stoynev, 2015).

За този период у нас, специализирани и подробни проучвания на скалните масиви са правени и продължават да се правят с оглед оценката на устойчивостта и оразмеряването скални откоси в открити рудници (Lakov, Stoinev, 2013; Lakov, 2018).

\section{Заключение}

Разгледаните в настоящата статия публикации (макар и в непълен обем) показват, че към настоящия момент изследователите в България са добре запознати с изискванията, методиките и нормативните документи, необходими за изследване устойчивостта на скални масиви в изкопи за различните видове строителство. На базата на резултатите от геоструктурно картиране на скални масиви, на 
проведените инженерногеоложки, хидрогеоложки и геотехнически проучвания са изготвени оценки за устойчивостта на скалните изкопи в редица кариери, откоси на инфраструктурни съоръжения и тунелни изработки.

Това, в значителна степен ще има благоприятен ефект във връзка с нуждите на инфраструктурното строителство, което се очаква в близко бъдеще и ще бъде свързано с проучване на около 5 пътни и 13 железопътни тунели, както и неопределен брой високи скални изкопи, съпътстващи строителството. Проектните съоръжения преминават през скални терени в сложни инженерногеоложки условия.

Благодарение на натрупания опит и познания в областта на геоструктурното картиране, инженерногеоложките и хидрогеоложки проучвания и геотехнически изследвания, можем да кажем, че предстоящите проблеми при проучването и проектирането на съществуващи и нови съоръжения могат да бъдат успешно решени.

\section{Литература \\ References}

Angelov, K., B. Konstantinov, A. Lakov. 1993. Stability of the bas-relief of the Madara Horseman (NE Bulgaria). Geotechnical Engieneering of hard soil-soft rocks. Balkema, Roterrdam, 1045-1049.

Antonov, L., M. Ivanov, S. Kerekov, D. Yaranov. 1955. Geology and hydrotechnical construction in Bulgaria. Sofia, 327 p. (in Bulgarian).

Barton, N., By, T.L., Chryssanthakis, L., Tunbridge, L., Kristiansen, J., Løset, F., Bhasin, R.K., Westerdahl, H. and Vik, G. 1992. Comparison of prediction and performance for a $62 \mathrm{~m}$ span sports hall in jointed gneiss. Proc. 4th. int. rock mechanics and rock engineering conf., Torino. Paper 17.

Barton, N., Løset, F., Lien, R. and Lunde, J. 1980. Application of the Q-system in design decisions. In: Subsurface space, (ed. M. Bergman) 2, New York: Pergamon, 553-561.

Barton, N.R., Lien, R. and Lunde, J. 1974. Engineering classification of rock masses for the design of tunnel support. Rock Mech. 6(4), 189-239.

Bieniawski, Z.T. 1973. Engineering classification of jointed rock masses. Trans S. Afr. Inst. Civ. Engrs 15, 335-344.

Bieniawski, Z.T. 1976. Rock mass classification in rock engineering. In: Exploration for rock engineering, proc. of the symp. (ed. Z.T. Bieniawski), 1, 97-106. Cape Town: Balkema.

Bieniawski, Z.T. 1989. Engineering rock mass classifications. New York: Wiley.

Deere, D.U., Hendron, A.J., Patton, F.D. and Cording, E.J. 1967. Design of surface and near surface construction in rock. In Failure and breakage of rock, proc. 8th U.S. symp. rock mech., (ed. C. Fairhurst), 237-302. New York: Soc. Min. Engrs, Am. Inst. Min. Metall. Petrolm Engrs.

Dobrev, N., E. Avramova-Tacheva, Bl.Košták. 2008. Geoarchaeology and Archaeomineralogy. Proceedings of the International Conference, 29-30 October 2008 Sofia, Publishing House "St. Ivan Rilski", Sofia, 385-390.

Dobrev, N., G. Frangov. 2000. Destructive geological processes endangering "Aladja Manastir' rock monument. Mining and Geology Magazine, 6-7, 11-15 (in Bulgarian).

Dobrev, N., I. Vasilev, V. Hristov, M. Krastanov. 2012. New approach for estimanion of the slope instability hazard on the slopes of the open-pit mines. BAS, Engineering geology and hydrogeology, Sofia, 26, 27-44 (in Bulgarian). 
Frangov, G., N. Dobrev. 2000. Destructive processes affected the rock "Aladja Monastery", NE Bulgaria. In: 8th International AEG Congress/8ème Congrès International de $A I G / C)$ 2000, Balkema, Rotterdam.

Frangov, G., P. Ivanov, N. Dobrev, Il.Iliev. 1992. Stability problems of the rock monument Madara horseman. 7 th. International congress on Deterioration and conservation of Stone, Lisbon, Portugal, June 15-18, 1425-1434.

Hoek, E., P. Marinos, M. Benissi. 1998. Applicability of the Geological Strength Index (GSI) classification for very weak and sheared rock masses. The case of the Athens schist formation. Bulletin of Engineering Geology and the Environment 1998; 57(2), 151-160.

Hoek E, Marinos P, Marinos V. 2005. Characterization and engineering properties of tectonically undisturbed but lithologically varied sedimentary rock masses. International Journal of Rock Mechanics and Mining Sciences 2005; 42(2):27785.

Hoek E, Marinos PG. 2000. Predicting tunnel squeezing problems in weak heterogeneous rock masses. Tunnels and Tunnelling International 2000;132(11):45-51.

Hoek E., J.W Bray. 1981. Rock Slope Engineering. London: 3rd edn. CRC Press, 364 p.

Hoek E.; Brown E.T. 1980. Empirical strength criterion for rock masses. Journal of the Geotechnical Engineering Division, 1013-1025.

Ilov, G. 2004. Constructional rock mechanics. Sofia, ERA, 285 p. (in Bulgarian).

Ivanov, Pl., B. Berov, N. Dobrev. 2018. Terrains mapping for rockfall vulnerability. $B A S$, Engineering geology and hydrogeology, Sofia, 32, 31-38 (in Bulgarian).

Jelev, V., A. Lakov, G. Aydanliiski, T. Georgieva. 2011. Geostructural and engineering geological study of „Yurtdere“ Quarry. I. Geostrucutral study. Ann. University of Mining and Geology, Sofia, V. 54, section 1, 33-38 (in Bulgarian).

Konstantinov, B. A. Lakov, St. Stoynev. 2003. Geotechnical problems of the cultural heritage immovable monuments in Bulgaria. Cultural heritage immovable monuments, Sofia, V. 46, section 1, 273-276 (in Bulgarian).

Konstantinov, B., S. Stoynev, A. Lakov, K. Anguelov, V. Jelev. 1996. Geological factors for the rockfall on the site of the Preobrajenie Monastery (Bulgaria). FGMU Beograde, Department of Geotechics, The international conference Trends in the devolepment of Geotechnics, Beograde 18-19, 590-593.

Koseva, Ch., A. Lakov, D. Karastanev. 1984. Study of the stress state and the stability of the faces of Elatzite open-pit mine during the excavation works. Ann. University of Mining and Geology, Sofia, v. XXX /1983-1984/ section IV, 137-143 (in Bulgarian).

Lakov, A. 2018. Rock slopes stability in open-pit mines and quarries. $\mathrm{PhD}$ thesis, University of Mining and Geology "St Ivan Rilski", Sofia, 138 p. (in Bulgarian, unpublished).

Lakov A., I. Paskaleva. 2009. Stability of the rock cliff at the site the rock church "Our Lady" near Ivanovo, Russe region. In: Protection of Historical Buildings, London, $155-160$.

Lakov, A., Stoynev, S. 2013. Defining Hoek and Brown failure criterion for rocks from simple strength laboratory tests data. Proceedings of the XII National Conference of the open pit and underground mining of minerals, 26-30 June 2013, Varna, Bulgaria, 218-225.

Lakov, A., St. Stoynev. 2015. Geotechnical conditions of „Kresna“ tunnel from „Struma“ highway. Ann. University of Mining and Geology, Sofia, V. 58, section $1,178-185$ (in Bulgarian). 
Lakov, A., St. Stoynev. 2016. Geotechnical conditions of „Jeleznitsa“ tunnel from „Struma“ highway. Ann. University of Mining and Geology, Sofia, V. 59, 1, 209214 (in Bulgarian).

Lakov, A. V. Jelev, G. Aydanliiski, T. Georgieva. 2011. Geostructural and engineering geological study of „Yurtdere“ Quarry. II. Rock-mass properties. Ann. University of Mining and Geology, Sofia, V. 54, 1, 139-144.

Lauffer, H. 1958. Gebirgsklassifizierung für den Stollenbau. Geol. Bauwesen 24(1), $46-51$.

Marinos P, Hoek E. 2000. GSI e a geologically friendly tool for rock mass strength. In: Proceedings GeoEng 2000, International conference on geotechnical and geological engineering. Melbourne, Australia, Lancaster, PA: Technomic Publishing Co.; 2000. 1422-1440.

Marinos P, Hoek E. 2001. Estimating the geotechnical properties of heterogeneous rock masses such as flysch. Bulletin of Engineering Geology and the Environment 2001; 60(2): 85-92.

Marinos V, Carter TG. 2018. Maintaining geological reality in application of GSI for design of engineering structures in rock. Journal of Engineering Geology 2018, 239, 282-297.

Marinos V, Marinos P, Hoek E. 2005. The geological strength index: applications and limitations. Bulletin of Engineering Geology and the Environment 2005; 64(1), $55-65$.

Marinos V. 2017. A revised geotechnical classification GSI system for tectonically disturbed rock masses, such as flysch. Bulletin of Engineering Geology and the Environment 2017, 19:1e14

Paskaleva, I., A. Lakov, N. Nikolaev, V. Parushev. 2009. Drilling-induced vibrations in rock church "Our Lady"- Ivanovo, Russe, NE Bulgaria. In: Protection of Historical Buildings, London, 1411-1415.

Protodyakonov, M. 1931. Rockmass pressure and mining support/. S. 1, Moscow, 104 p. (in Russian).

Sachkov, D., K. Karsheva, Iv. Dimitrov, N. Dobrev. 2012. Blocks-size estimation of the crystaline schists on the example of Granitovo ore field, Yambol district. BAS, Engineering geology and hydrogeology, Sofia, 26, 45-5 (in Bulgarian).

Stoynev, St., A. Lakov. 2018. Geotechnical conditions of „Stara Kresna“ tunnel from „Struma“ highway. Ann. UASG, Sofia, V. 51, no. 7, 35-48 (in Bulgarian).

Terzaghi, K. 1946. Rock defects and loads on tunnel supports. In: Rock tunneling with steel supports, (eds R. V. Proctor and T. L. White) 1, 17-99. Youngstown, OH: Commercial Shearing and Stamping Company.

Wickham, G.E., Tiedemann, H.R. and Skinner, E.H. 1972. Support determination based on geologic predictions. In: Proc. North American rapid excav. tunneling conf., Chicago, (eds K.S. Lane and L.A. Garfield), 43-64. New York: Soc. Min. Engrs, Am. Inst. Min. Metall. Petrolm Engrs. )

Постьпила: 10.12 .2019

Приета: 07.01.2020
Received: 10 December 2019 Accepted: 07 January 2020 